\title{
Soundscape quality analysis by fuzzy logic: A field study in Cordoba, Argentina
}

\author{
Arturo Maristany, Manuel Recuero López, Cesar Asensio Rivera
}

\begin{abstract}
This research studies urban soundscapes through the comparative analysis of twelve public open spaces in the city of Córdoba (Argentina), taken as case studies. The work aims to examine selection of indicators and assessment tools intended to characterize soundscape quality. The field study was carried out through surveys and acoustic and psychoacoustic indicators, that are used together to objectively describe the sound quality of urban spaces.

The study shows that, while there is a relationship of these indicators with the sound quality of the spaces, this is not linear. Their relative importance or influence depends on the interrelations occurring between the parameters studied. A model analyzing and correlating the parameters with the sound qual ity, based on the postulates of fuzzy logic, was applied as a tool of analysis, and it was seen to achieve a very clase approximation to the subjective or perceptual response of the inhabitants. This clase match between the model results and the perceptual response of the users confirms the fuzzy modelas an effec tive tool for the study, not only of soundscapes, but also for those situations in which objective param eters must be related to the perceptual response of users.
\end{abstract}

\section{Introduction}

The evaluation of sound is a complex system that relates vari ous disciplines: acoustics, physiology, sociology, psychology, anthropology and statistics [1,2). Research conceming the problem of urban noise has focused on two main areas considered priority for their impact on city populations: quantitative analysis of acous tic conditions $(3,4)$ and subjective evaluation ofthe response of the inhabitants [5 9).

In recent times, there is a tendency to pay attention not only to the negative aspects of sound, mainly discomfort, but also to the sound qualityofthe space (10 12). This approach involves the con cept of "sound environment design" as a stage beyond the control or reduction of noise to acceptable limits. It involves a comprehen sive methodological development that takes the interaction between people, sound and context into account (13 17).

The urban soundscape normally consists of a mixture of various sounds with varying intensities, directions and durations, which makes its assessment more difficult (18). Sound sources are analyzed not only from the physical point of view, by means of acoustic indicators, but semantically, looking for the mean ings that sound has for the population and the specific users (19 23). This analysis is usually conducted through a study based on the appli cation of opinion polls on site simultaneously with

Ambient sound can cause subjective reactions, and may be appropriate, pleasant, familiar, useful for orientation, irritating, among others. Such attributes, and their meanings, respectively have a great impact on the assessment of the soundscape (28 31). The soundscape cannot be studied independently. The condi tion of comfort of an environment is the result of the integration of severa) factors, one of which is the acoustic. It is evident that the response of tolerance or discomfort toa sound stimulus is con ditioned by other visual, therrnal and/or multisensory factors (32 39).

Different authors have begun recently to apply the psychoa coustic descriptors, originally developed to define the sound qual ity of products (40 44), to the assessment of environmental situations such as soundscapes (45 47). Psychoacoustics studies sound from the point of view of its subjective perception, Jooking for relationships between the physical stimulus and the psycholog ical response that it causes in people. Applying this type of descrip tors can help in the evaluation of soundscape quality, relating ambient sound with the Jevel of anticipated discomfort. 
This study analyzes a set of urban public spaces located in the central area of the city of Córdoba, in Argentina. The study of the sound quality of public spaces in the city center enables the anal $y$ sis of the different reactions and degree of acceptance of the users of urban open spaces in which the objective sound conditions are similar. A methodological approach is proposed for the analysis of the soundscape, based on a mechanical practice for objective evaluation, integrating and interrelating the acoustic descriptors selected through a system of fuzzy logic. The importance of fuzzy logic [48] is based on its similarity with human reasoning, tending to obtain results that are not necessarily exact but are rather per fectible. Fuzzy logic has been used successfully in several studies related to the problem of noise in relation to aspects such as the modelling of working efficiency in noisy environments [49]; defini tion of discomfort from noise [50,51]; prediction of train noise [52]; and interference in communication [53].

\section{Methodology}

\subsection{Field of study}

Fig. 1 shows the location of the twelve public spaces, squares and promenades analyzed, which make up the main network of public spaces in the city center. All of the spaces have common character istics that were taken as a starting point for their selection: they are in areas of high population and building density, are bordered with avenues and streets with high traffic levels, and together make up the main network of urban spaces corresponding to the central area of the city. The differences between the mentioned cases can be seen in their shape, the ratio of green areas to paved areas and especially in their function. Urban spaces can be arranged according to their main purpose, as squares, suitable for relaxation ( $\mathrm{Pa} \mathrm{Sb}, \mathrm{Pl} \mathrm{Es}$ ), meet ing or strolling (PI VS, PI SM, Pl Co, Pl It); pedestrian areas intended for circulation with a significant presence of bars (Plz F) and shops (Pt CJ, Pt SC); markets (Pa BP, Pa Ar), and recreation spaces used for informal sports activities (PI In).

\subsection{Acoustic measurements}

Objective acoustic assessment of the urban spaces in this study was performed by means of noise measurements followed by sta tistical noise analysis in the inner areas of the spaces and at their perimeters, coinciding with vehicle traffic routes. The parameters measured were $L_{\text {Aeq, }}, L_{\text {Ceq }}$, percentiles $L_{N}(N=1,5,10,50,90,95$, 99) and $L_{\text {Zeq }}$ in third octave bands from $12.5 \mathrm{~Hz}$ to $20 \mathrm{kHz}$. The measurements were performed with a Brüel \& Kjær type 2250 sound level meter equipped with software for analysis in frequency BZ 7223.
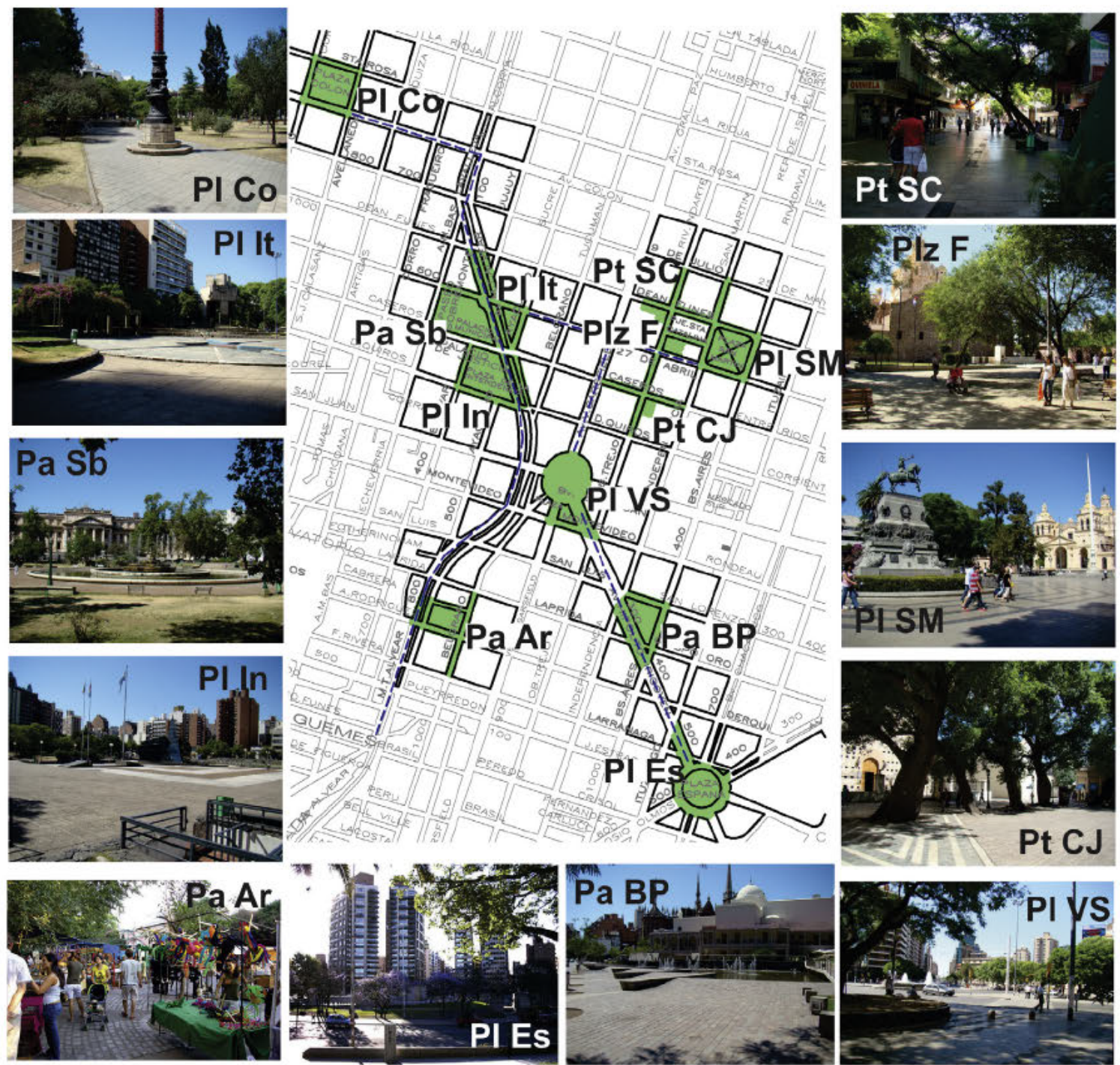

Fig. 1. Location of the spaces analyzed.

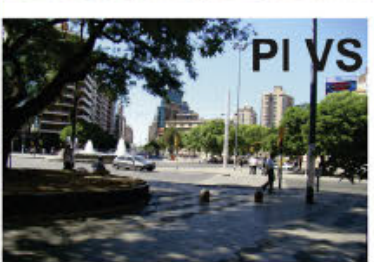


The number and location of the measurement points were determined with the criterion of surveying the general behavior of the area: the edge situation of each of the areas analyzed, and the specific behavior of each space in the interior of the squares, simultaneously with the subjective survey. The times chosen were those of greatest activity and greatest traffic flow in the central area, on weekdays between $10 \mathrm{am}$ and $5 \mathrm{pm}$.

The number of internal or external points of each sector ana lyzed was defined on the basis of the formal characteristics of each space and the number of surrounding high traffic routes. Consider ing the necessity of simultaneous subject and noise level surveys, the duration of the measurements was set according to the dura tion of the opinion polls, with a period from 5 to $15 \mathrm{~min}$. For the minimum period of 5 min adopted, it is known [54] that the mar gins of error in urban noise measurements remain within permis sible values and similar to greater periods of up to $15 \mathrm{~min}$, always following the indications of ISO 19962 , which recommends the adoption of a time range for measurement that covers all the sig nificant variations in the emission and propagation of noise.

\subsection{Psychoacoustic descriptors}

Simultaneously with the measurements of the physical param eters and the subject surveys, a recording was made of each sound scene for subsequent analysis. The recordings were made with a Zoom digital recorder model $\mathrm{H} 4 \mathrm{n}$, with two XY stereo condenser microphones and audio recording up to $24 \mathrm{bit} / 96 \mathrm{kHz}$, with a sam pling frequency of $44.1 \mathrm{kHz}$. PsySound 3 software, intended for the analysis of sound recordings based on physical and psychoacoustic algorithms, developed under the Matlab environment, was used for calculating the acoustic descriptors [55].

The psychoacoustic descriptors calculated by PsySound3 were: loudness, sharpness and roughness. The Psysound3 analysis mod ules used under Matlab environment also enables the spectrum to be calculated by one third band, the respective levels and the specific loudness pattern. For loudness calculation this analyzer implements the dynamic loudness model of Chalupper and Fastl. This model uses the Bark critical band rate scale to model auditory filters. An auditory temporal integration is included in the loudness model. For sharpness calculation, it uses the Aures model and for the roughness, implements the roughness algorithm of Daniel and Weber [48]. The $1 / 3$ octave spectrum, the equivalent continu ous sound level and the loudness calculated by software were com pared with those measured simultaneously with the BK2250 sound level meter. The variations and errors detected were low, and they were seen not to influence the type of analysis in process.

\subsection{On site survey}

Simultaneously with the acoustic measurements, user opinion polls were conducted in each of the urban spaces under study. The questionnaire examines general sociological and particular aspects in relation to the physical space to evaluate and the char acterization of its soundscape. The survey responds to practical application criteria based on other experiences of this kind taken as a model [56]. A total of 416 surveys, consisting of 8 questions, were applied in the twelve spaces, taking from 5 to 10 min each.

The first four questions referred to the age, sex and activity of the people: motivations for the use of the space, distance from the area where they live, and the average time they remain there. Questions 5 and 6 evaluate the soundscape quality in particular and the environment in general, with a bipolar scale of five points with the response alternatives: "very good", "good", "fair", "bad" and "very bad". Question 7 focuses specifically on identifying types of sounds, split into three categories: (1) human sounds, (2) natural sounds, and (3) technological sounds. For each of the three cate gories, the degree of perception was indicated and the level of plea sure or discomfort of it during a visit to the area. Responses were given on a five point category scale, with the response alternatives "not heard", "heard a little", "sometimes heard", "heard a lot" and "completely dominant". The aim of the scale is to represent the degree of presence of each sound perceived by each user individu ally. The level of satisfaction is also evaluated on a five point scale, with response alternatives: "pleasant", "quite pleasant", "fair", "quite annoying" and "annoying".

\subsection{Fuzzy logic analysis}

The use of a system is proposed that aims to qualify urban spaces through analysis by fuzzy logic of the acoustic and psychoa coustic indicators or descriptors that are identified as traits of the sound quality of the soundscape.

A diffuse or fuzzy system is structured in three fundamental stages: fuzzification or diffusion of the input variables, inference through assessment and formulation of control rules, and defuzzi fication or de diffusion to calculate the output results (Fig. 2). For practical calculation purposes, we used the Matlab ${ }^{\circledR}$ fuzzy logic toolbox. The inference process used corresponds to the Mamdani criterion and the technique adopted for defuzzification is the cen troid method.

At the fuzzification or diffusion stage, the inputs are selected and the degree of belonging of each of the fuzzy sets from member ship functions related to each descriptor. For each input variable, the range and the degree of belonging to a fuzzy linguistic set was defined ( $0100 \%)$. In this work, membership or belonging functions used are trapezoidal.

The rules are a list of "if then" type statements. The part corre sponding to the "if" is the antecedent and lists the condition(s) related to the inputs belonging to a particular fuzzy set. The second part is the consequent and indicates the set to which the outputs of the system must belong to the extent that it complies with the cor responding antecedent. In defuzzification, the fuzzy sets that rep resent the results of each rule are combined into a single final fuzzy set.

\section{On site survey results and discussion}

\subsection{Qualitative survey}

Table 1 shows the number of respondents in each space, together with the data resulting from the initial questions: age, sex and activity. It can be seen that the respondents are distributed almost equally by gender: men (57\%) and women (43\%). More than half of those surveyed live in the area (25\%) or in a nearby neigh borhood (32\%) and the predominant activity is walking or relaxing.

Table 2 lists, for each space studied, the percentage of intervie wees who consider that the sound quality of the place is very good to very bad. Taking a value of 5 as "very good" and a value of 1 as "very bad", the weighted average of the percentages was calculated to give the final value.

Fig. 3 summarizes all the responses for the overall analysis of the quality of the space, representing the quality level by the weighted average.

The graphs of Figs. 4 and 5 show the percentages of intervie wees who considered as high the levels of presence and acceptance for the urban zones classified as squares, pedestrian, market and recreational spaces.

A strong presence of technological sounds is found, mainly the noise of vehicle traffic, followed by the presence of sounds of human origin and finally natural sounds. Acceptance levels are variable, showing a tendency toward greater acceptance of natural 


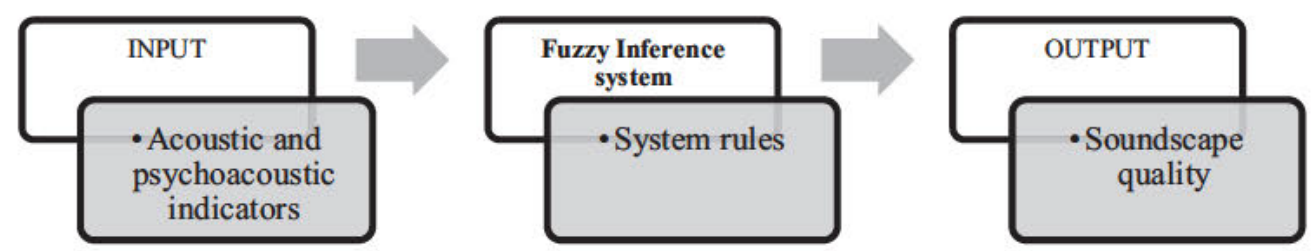

Fig. 2. Basic structure of the proposed system.

Table 1

Data resulting from the initial questions.

\begin{tabular}{llrl}
\hline & & Total & Percent \\
\hline Gender & male & 229 & 57 \\
Age & female & 175 & 43 \\
& $18-30$ & 195 & 48 \\
Lived in & $31-50$ & 177 & 44 \\
& over 50 & 32 & 8 \\
& the area & 101 & 25 \\
Activity & a nearby neighborhood & 130 & 32 \\
& a distant neighborhood & 137 & 34 \\
& another city & 36 & 9 \\
& in passing & 70 & 17 \\
& for a walk & 84 & 20 \\
& to read a book & 15 & 4 \\
& to relax & 180 & 42 \\
& to do sport & 25 & 6 \\
& others & 50 & 12 \\
& less than one hour & 188 & 47 \\
& about one hour & 55 & 14 \\
& up to two hours & 27 & 7 \\
& over two hours & 27 & 7 \\
& it depends & 104 & 26 \\
\hline
\end{tabular}

and human sounds rather than technological. The acceptance or discomfort level depends in all cases on the type of activity, with market or recreational activity spaces having a higher acceptance level for sounds of human origin such as conversations or music. Spaces for strolling and resting are seen as positive when the level of presence of natural sounds increases, and so sounds of human origin are rated as discomfort when their level of presence tends to mask natural sounds.

Recreational areas are seen to generally have a higher level of acceptance of technological sounds than the others. The responses of acceptance or pleasure produced in the user by the urban space are related not only with urban space quality environment indica tors, but also with their use. When natural or human sounds have a level of presence sufficient to stand out above technological sounds, the latter are not definitive in the overall acoustic rating.

\subsection{Acoustic measurements}

Tables 3 and 4 list the average values for the $L_{\text {Aeq }}$ and $L_{N}$ param eters resulting from the measurements at inner and outer points of the urban spaces. The results of measurements at outer perimeter points reflect the strong incidence of traffic noise in all the environ ment of the areas studied. In all cases, these mark over $72 \mathrm{dBA}$ of continuous equivalent sound level, while toward the interior of the spaces they are between 65 and $70 \mathrm{dBA}$. The reduction of sound level toward the interior of the squares is about $510 \mathrm{~dB}$. The very marked difference of about $10 \mathrm{~dB}$ between $L_{10}$ and $L_{90}$ shows the great variation in traffic flow during the measurement period. The reduction of sound level depends, among other aspects, on the distance between the inner and outer points. The spaces with higher propagation attenuation have a total width between 100 and $110 \mathrm{~m}$, while the small squares and pedestrian areas arent exceeding $50 \mathrm{~m}$. In all cases they are completely surrounded by buildings from 10 to $15 \mathrm{~m}$ high that characterizes the central area.

The graph in Fig. 6 shows the low correlation between the sound levels surveyed and the acoustic rating of each space. The sound quality of open urban spaces can be good or very good despite sound levels being higher than $60 \mathrm{dBA}$. It can also be noted that in spaces for resting or strolling, quality increases with the reduction of sound level, while in spaces for recreation, craft mar kets, pedestrian or commercial areas, the relation is not in accor dance and visitors accept higher sound levels, but never above $65 \mathrm{dBA}$. Generally, nearly all the studies made agree that the strength of the sound is recognized as one of the important factors. The classic indicators of sound level seem useful for describing this first factor of the soundscape, although this does not mean that the indicator must necessarily be the $L_{\text {Aeq }}[11]$.

The $L_{\text {Ceq }} L_{\text {Aeq }}$ difference is seen to be a good descriptor of the low frequency content of the urban sound scene. In general, urban spaces with low sound levels and normal sound quality have a high $L_{\text {Ceq }} L_{\text {Aeq }}$, derived from the exclusive presence of low frequency sound from traffic.

The $L_{10} L_{90}$ difference is also an important indicator, but diffi cult to classify, for characterizing a soundscape. A high value is related with the possibility of perceiving the main sounds of the space above the background sound. The spaces are rated as good as long as the difference means that the characteristic sounds of the space stand out above the background noise and it is not the result of temporary variations of intrusive noise. In some cases there is a significant difference of $L_{10} L_{90}$ produced by the tempo rary fluctuation of sounds of technological origin and the environ ment is this case is considered negative.

\subsection{Psychoacoustic descriptors}

The graphs in Figs. 7 and 8 compare the values of sharpness and loudness with the resulting perceptual sound quality. A significant

Table 2

Sound quality of each particular space.

\begin{tabular}{|c|c|c|c|c|c|c|c|c|c|c|c|c|}
\hline & $\mathrm{Pa} \mathrm{Sb}$ & PI In & $\mathrm{Pa} \mathrm{BP}$ & Pt SC & $\mathrm{Pa} \mathrm{Ar}$ & PI It & PI SM & Pt C & PI Co & PI Es & Pl VS & Plz F \\
\hline Very good (5) & $26 \%$ & $5 \%$ & $9 \%$ & $20 \%$ & $6 \%$ & $2 \%$ & $0 \%$ & $7 \%$ & $3 \%$ & $0 \%$ & $0 \%$ & $0 \%$ \\
\hline Good (4) & $42 \%$ & $57 \%$ & $30 \%$ & $20 \%$ & $26 \%$ & $32 \%$ & $17 \%$ & $10 \%$ & $9 \%$ & $5 \%$ & $0 \%$ & $0 \%$ \\
\hline Neutral (3) & $19 \%$ & $24 \%$ & $46 \%$ & $40 \%$ & $35 \%$ & $27 \%$ & $47 \%$ & $37 \%$ & $28 \%$ & $34 \%$ & $27 \%$ & $0 \%$ \\
\hline Bad (2) & $10 \%$ & $7 \%$ & $13 \%$ & $10 \%$ & $24 \%$ & $37 \%$ & $30 \%$ & $37 \%$ & $38 \%$ & $45 \%$ & $53 \%$ & $60 \%$ \\
\hline Very bad (1) & $3 \%$ & $7 \%$ & $2 \%$ & $10 \%$ & $9 \%$ & $2 \%$ & $6 \%$ & $10 \%$ & $22 \%$ & $16 \%$ & $20 \%$ & $40 \%$ \\
\hline Weighted average & (3.8) & (3.5) & (3.3) & $(3.3)$ & $(3.0)$ & $(3.0)$ & $(2.8)$ & (2.7) & $(2.3)$ & $(2.3)$ & (2.1) & (1.6) \\
\hline
\end{tabular}




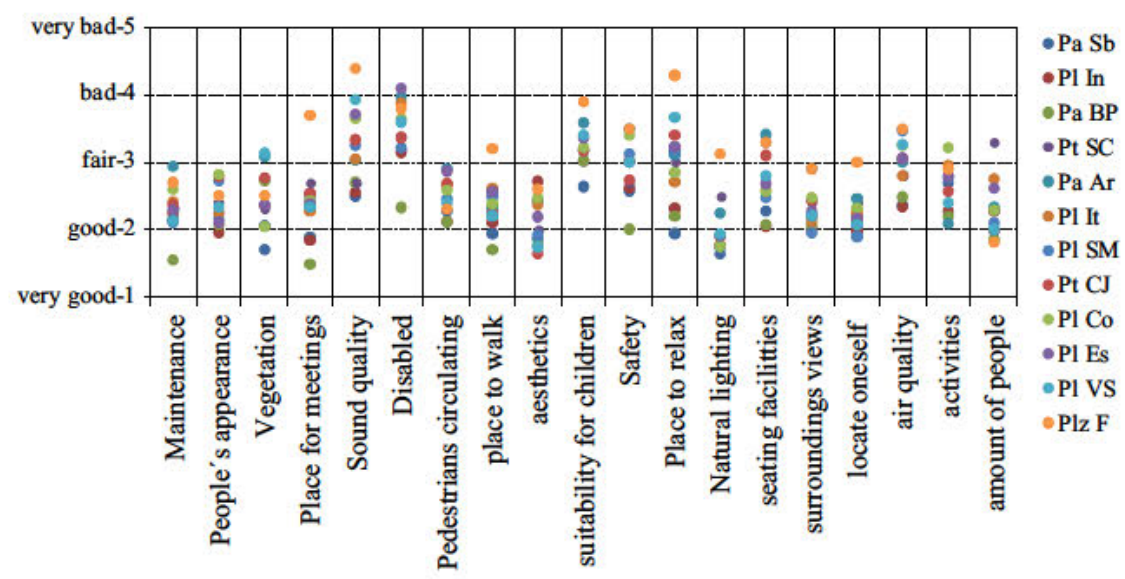

Fig. 3. Overall environmental rating of urban spaces.

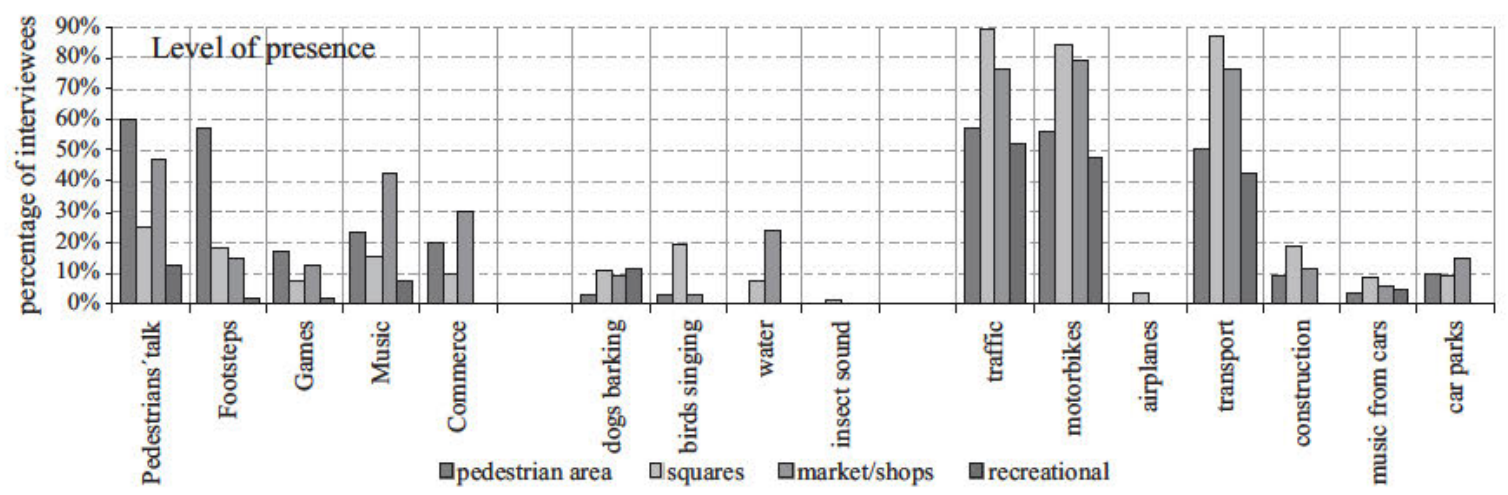

Fig. 4. Levels of presence for urban areas classified as squares, pedestrian, markets and recreational spaces.

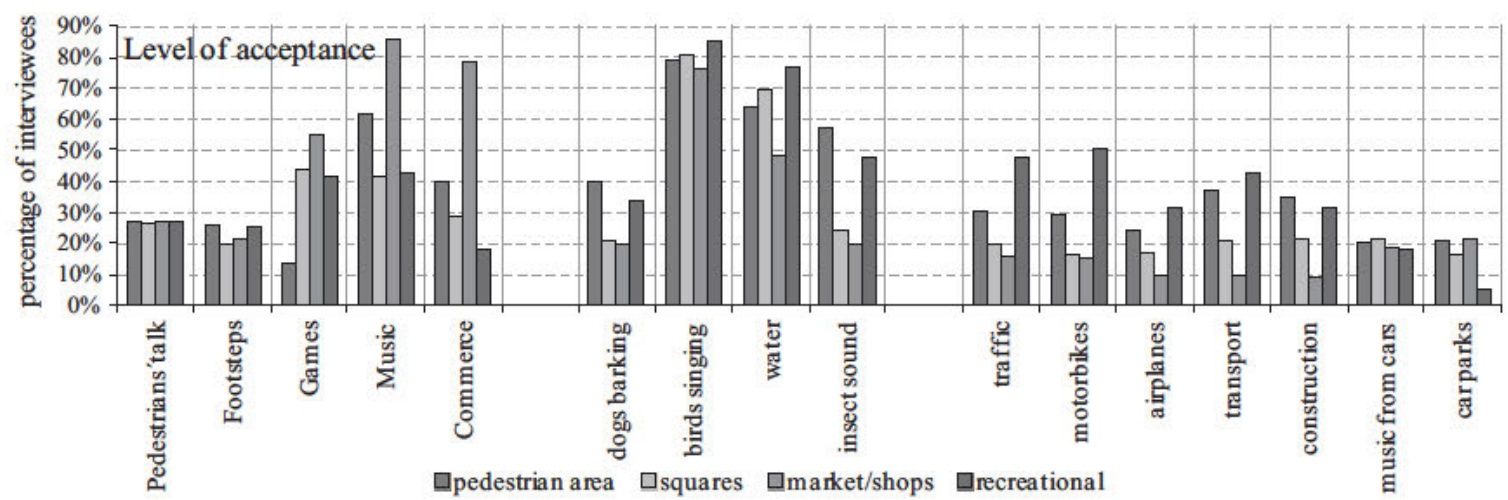

Fig. 5. Levels of acceptance for urban areas classified as squares, pedestrian, markets and recreational spaces.

Table 3

Average interior sound levels: $L_{N}$ and $L_{\text {Aeq }}(\mathrm{dBA})$.

\begin{tabular}{|c|c|c|c|c|c|c|c|c|c|c|c|c|}
\hline & $\mathrm{Pa} \mathrm{Sb}$ & PI In & PI It & PI SM & Plz F & Pt SC & Pt CJ & $\mathrm{Pa} \mathrm{Ar}$ & $\mathrm{Pa} \mathrm{BP}$ & PI Es & Pl Vs & $\mathrm{Pl} \mathrm{Co}$ \\
\hline$L_{1}$ & 71.0 & 77.1 & 74.9 & 74.3 & 71.0 & 66.5 & 71.5 & 73.3 & 77.1 & 72.2 & 76.1 & 76.2 \\
\hline$L_{10}$ & 67.2 & 68.4 & 68.6 & 71.4 & 67.1 & 63.9 & 65.8 & 68.6 & 70.6 & 68.3 & 73.5 & 71.2 \\
\hline$L_{50}$ & 62.5 & 61.8 & 63.6 & 65.9 & 62.8 & 61.2 & 61.4 & 62.6 & 67.4 & 65.5 & 71.9 & 67.1 \\
\hline$L_{90}$ & 59.4 & 57.8 & 61.1 & 61.8 & 59.6 & 59.6 & 58.9 & 59.1 & 65.5 & 63.2 & 70.5 & 63.5 \\
\hline$L_{99}$ & 57.9 & 56.1 & 59.5 & 60.3 & 57.9 & 58.7 & 57.8 & 56.8 & 64.2 & 61.7 & 69.8 & 60.8 \\
\hline Mean $L_{\text {Aeq }}$ & 64.6 & 67.3 & 66.2 & 67.8 & 64.7 & 62.0 & 64.0 & 65.1 & 68.5 & 66.3 & 72.2 & 68.6 \\
\hline$L_{10}-L_{90}$ & 7.8 & 10.7 & 7.5 & 9.6 & 7.6 & 4.3 & 6.9 & 9.5 & 5.1 & 5.1 & 3.0 & 7.7 \\
\hline
\end{tabular}


Table 4

Average external sound levels: $L_{N}$ and $L_{\text {Aeq }}(\mathrm{dBA})$.

\begin{tabular}{|c|c|c|c|c|c|c|c|c|c|c|c|c|}
\hline & $\mathrm{Pa} \mathrm{Sb}$ & Pl In & PI It & PI SM & $\mathrm{Plz}$ F & Pt SC & Pt G & $\mathrm{Pa} \mathrm{Ar}$ & Рa BP & Pl Es & PI Vs & Pl Co \\
\hline$L_{1}$ & 85.9 & 83.2 & 84.5 & 85.1 & 79.0 & 83.0 & 81.9 & 80.1 & 84.0 & 84.9 & 80.2 & 82.8 \\
\hline$L_{10}$ & 76.9 & 74.5 & 78.0 & 78.8 & 73.8 & 77.7 & 77.1 & 73.7 & 76.2 & 77.2 & 76.9 & 77.2 \\
\hline$L_{50}$ & 69.1 & 68.3 & 72.3 & 71.5 & 68.2 & 71.9 & 72.2 & 66.5 & 70.1 & 71.6 & 73.3 & 72.0 \\
\hline$L_{90}$ & 63.6 & 63.4 & 68.0 & 64.9 & 63.1 & 66.9 & 66.6 & 58.7 & 65.5 & 68.2 & 70.9 & 66.6 \\
\hline$L_{99}$ & 60.2 & 60.3 & 65.0 & 62.9 & 61.3 & 63.8 & 63.3 & 55.5 & 63.9 & 66.6 & 69.9 & 62.1 \\
\hline Mean $L_{\text {Aeq }}$ & 74.7 & 72.1 & 75.0 & 75.5 & 70.5 & 74.3 & 74.2 & 70.4 & 73.2 & 74.2 & 74.3 & 73.9 \\
\hline$L_{10}-L_{90}$ & 13.3 & 11.1 & 10.0 & 13.9 & 10.7 & 10.8 & 10.5 & 15.0 & 10.7 & 9.1 & 6.0 & 10.6 \\
\hline
\end{tabular}

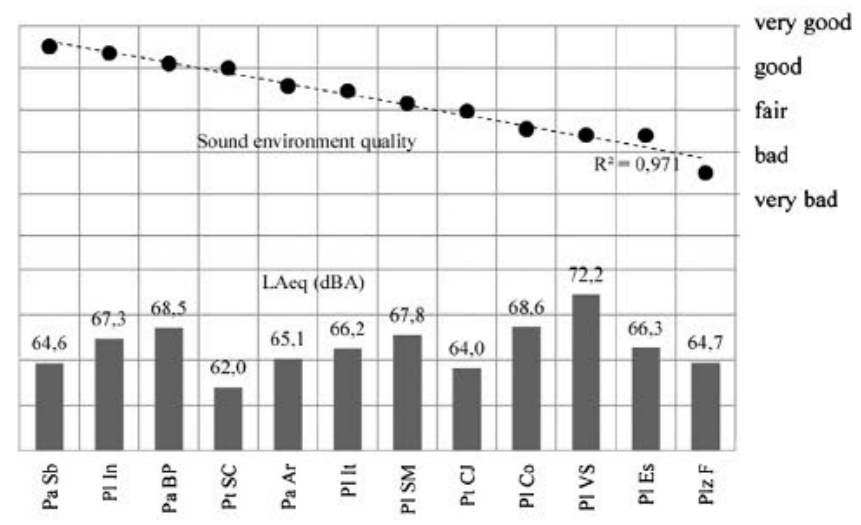

Fig. 6. Relation between sound quality and equivalent continuous sound level $L_{\text {Aeq }}$ within urban spaces.

Pearson correlation $(r=0.81)$ is noted between the trend lines of sound quality of the space and sharpness. The distancing of the trend line in some specific cases is related to other parameters ana lyzed: high level of loudness, high content of low frequencies (rep resented by $L_{\mathrm{Ceq}} L_{\mathrm{Aeq}}$ or $C_{o} G$ ) or a low figure background ratio (saturated soundscape). In the case of loudness, there is no direct ratio with perceptual sound quality (Pearson Correlation $r=0.19$ ). Loudness is seen to be related to discomfort from noise but not with the level of pleasure or acceptance of an urban scene or soundscape. In some of the twelve public spaces, up to three scenes were analyzed, thus achieving a total of 22 different sound scenarios.
Sound scenes with high sharpness values are characterized by the presence of music, active fountains of water, and people's con versations and voices. For assessing sound environments, the two basic psychoacoustic measurements, loudness and sharpness, proved to be effective for evaluating the volume and tone color of the sounds.

\section{Applying a fuzzy logic system}

\subsection{Description of the proposed system}

Following the analysis made, the descriptors or input data adopted are sharpness, loudness, $L_{\mathrm{Ceq}} L_{\mathrm{Aeq}}$ and $L_{10} L_{90}$. The ranges of input variables are set according to the values emerging from the survey of objective and psychoacoustic descriptors: sharpness (0 5 acum), $L_{\text {Ceq }} L_{\text {Aeq }}(420 \mathrm{~dB}), L_{10} L_{90}(2 \quad 15 \mathrm{~dB}$ ) and loudness ( 040 sones). The membership rules are made up in function of the quality associated with the range of the variable considered (e.g., Sharpness 1...5 acum; low, medium, high quality).

In the case of sharpness, loudness and the $L_{\text {Ceq }} L_{\text {Aeq }}$ difference, the linguistic sets chosen were "low", "medium" and "high", while for the difference of percentiles $L_{10} L_{90}$ they were only "low" and "high". Figs. 9 and 10 show the functions of belonging to the fuzzy set defined for each range.

The list of sentences or rules is defined indicating the action to be performed with each of the fuzzy sets analyzed at the previous stage. Fig. 11 shows a breakdown of the 11 rules adopted for the inference process.

The graph of Fig. 12 shows the membership function of the out put variable (sound quality). The function used is triangular in type.

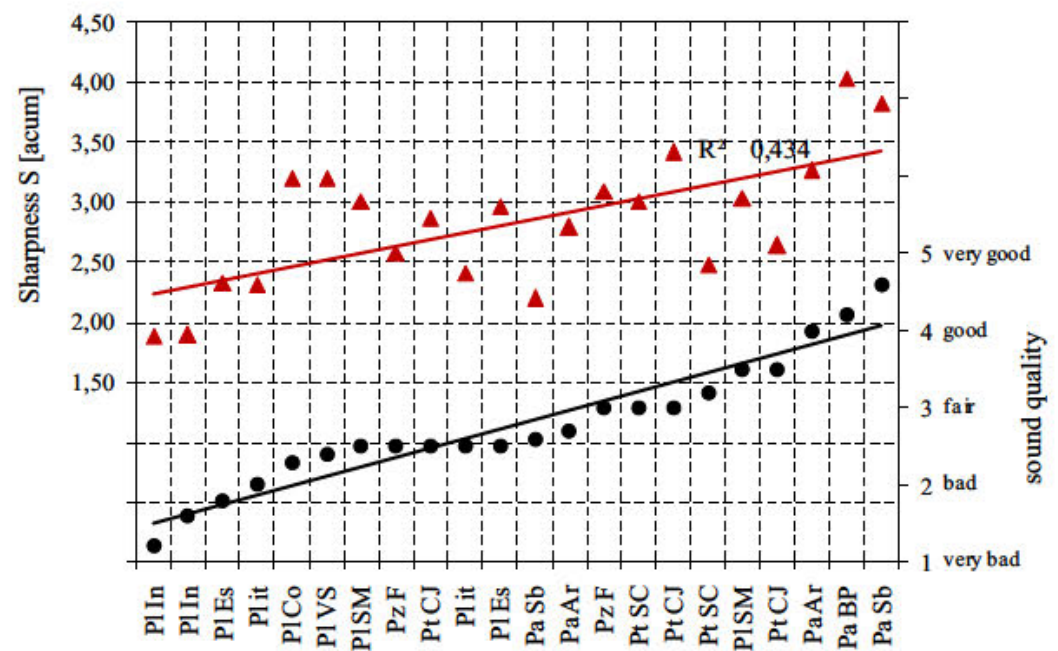

Fig. 7. Relationship between sharpness and sound quality. 


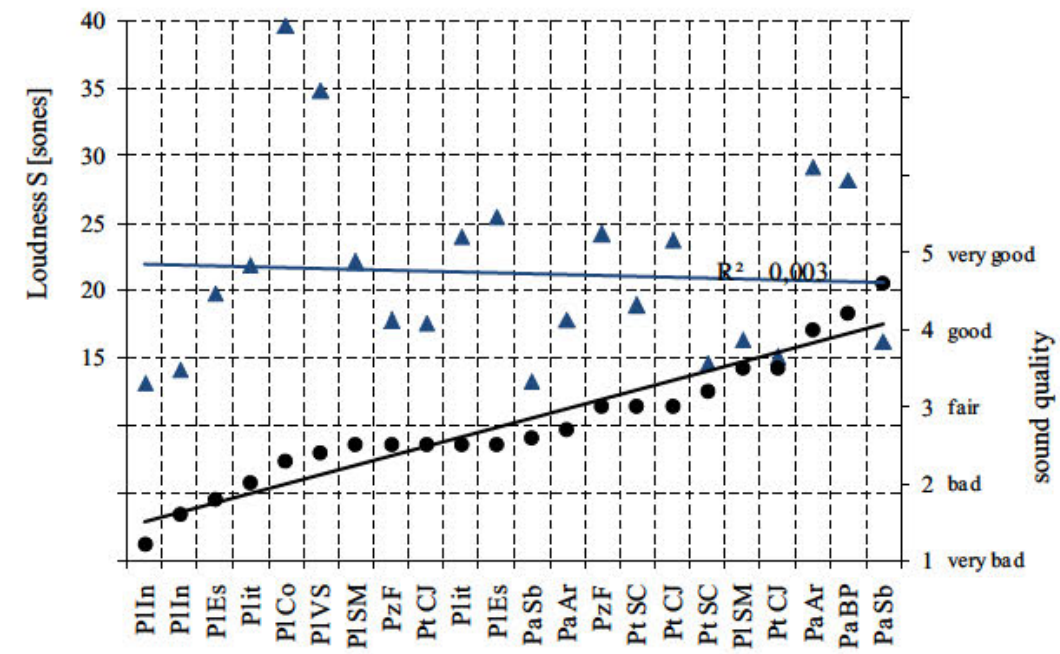

Fig. 8. Relationship between loudness and sound quality.

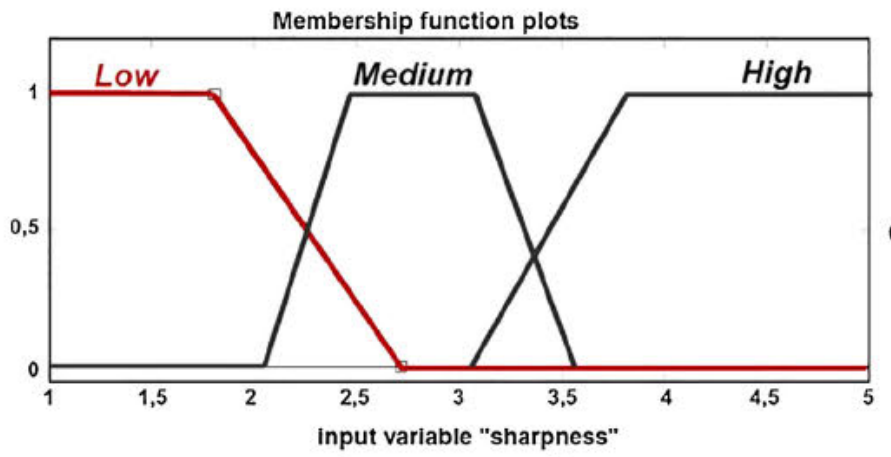

Low $\mu[x ; 1,1,1.80,2.70]$ acum

Medium $\mu[x ; 2.10,2.50,3.10,3.60]$ acum

high $\mu[x ; 3.1,3.8,5,5]$ acum

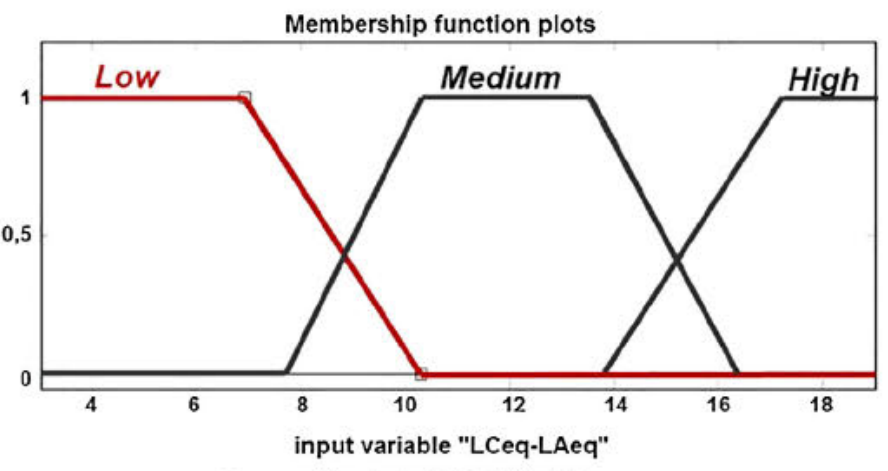

Low $\mu[x ; 1,1,6.90,10] d B$

Medium $\mu[x ; 7.7,10.3,13.6,16.50] d B$

High $\mu[x ; 13.8,17.20,19,19] d B$

Fig. 9. Functions of belonging for sharpness and $L_{C \text { Ceq }}-L_{\text {Aeq }}$.

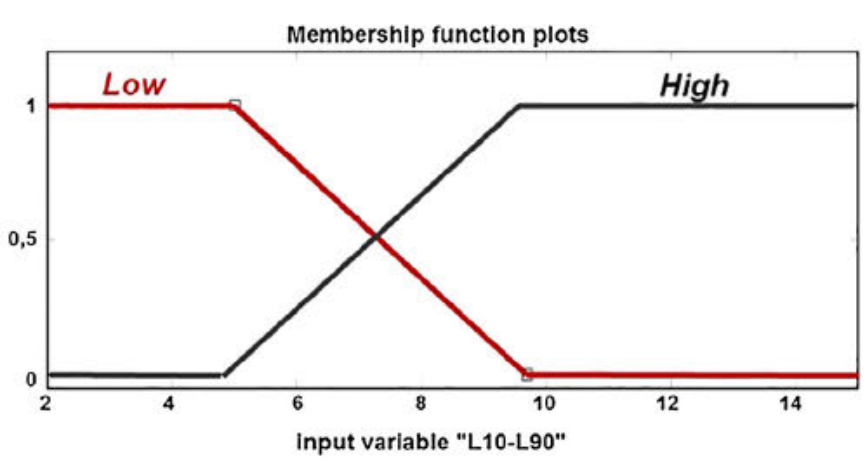

Low $\mu[x ; 2,2,5,9.70] d B$

High $\mu[x ; 4.90,9.60,15,15] d B$

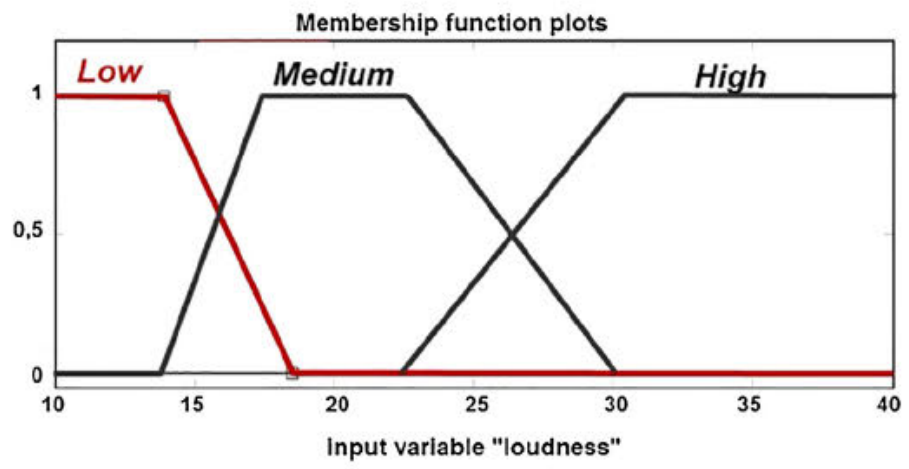

Low $\mu[x ; 1,1,14,18.5]$ son

Medium $\mu[x ; 13.8,17.4,22.7,30]$ son

High $\mu[x ; 22.4,30.4,40,40]$ son

Fig. 10. Functions of belonging for $L_{10}-L_{90}$ and loudness. 


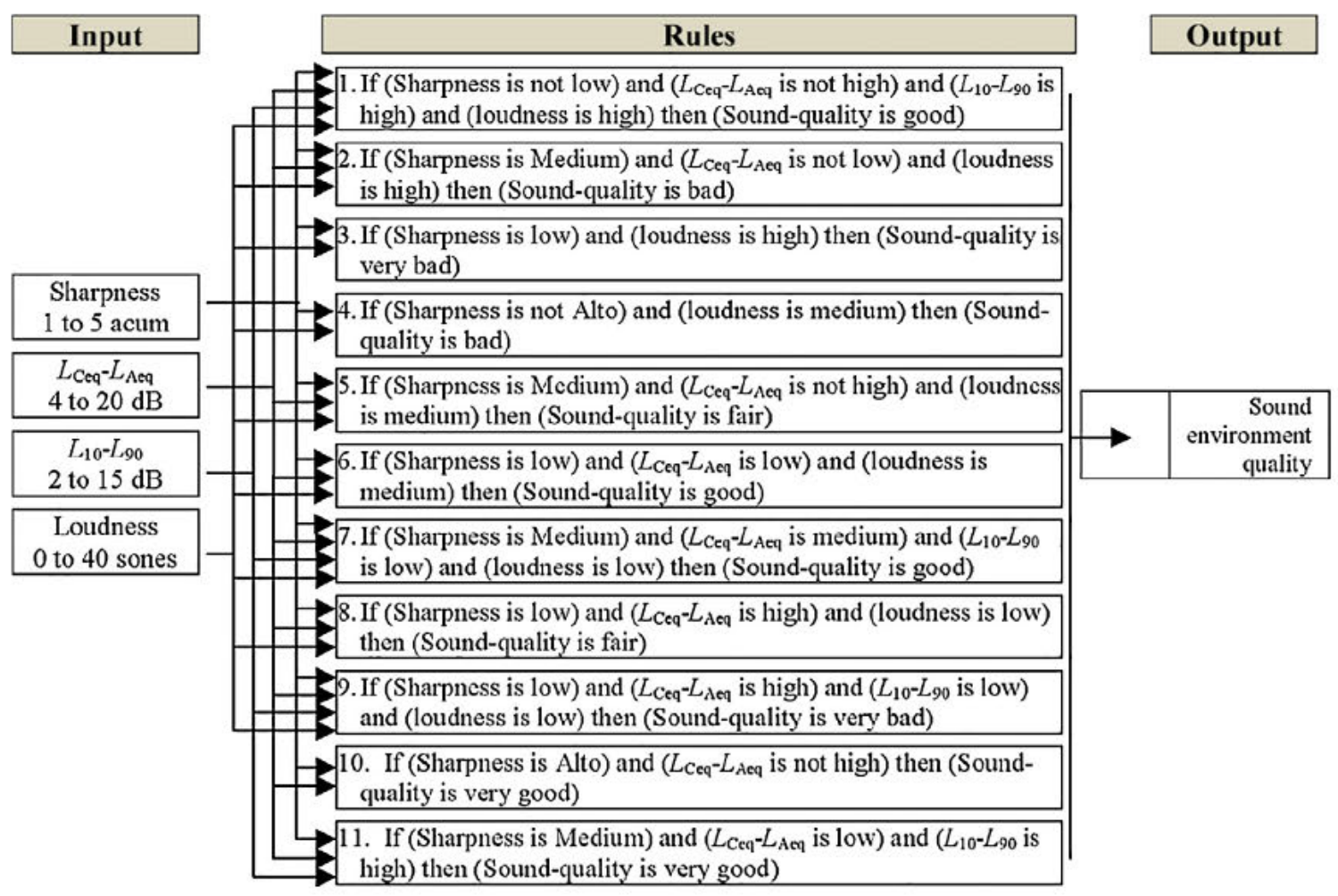

Fig. 11. Schedule of input, output variables and rules of the proposed system.

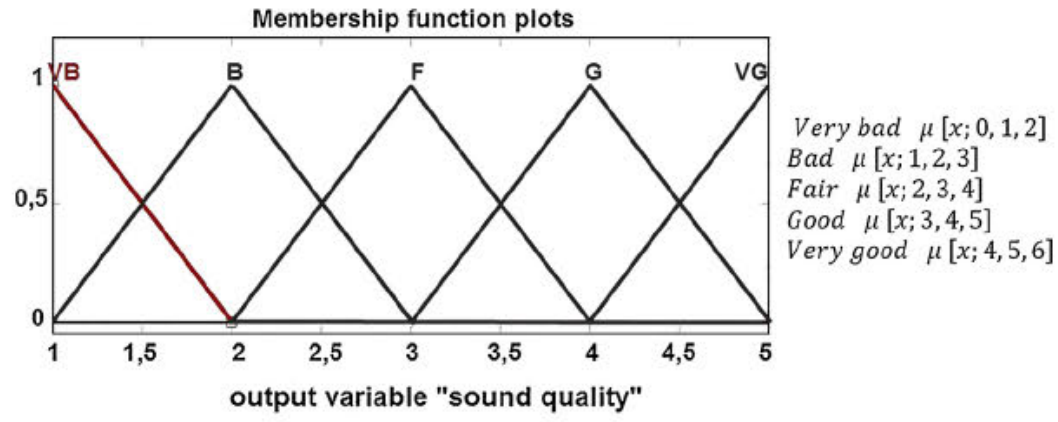

Fig. 12. Functions of belonging for sound quality.

\subsection{Results obtained}

The proposed fuzzy inference model was applied to the exterior urban spaces studied in the course of this work. Table 5 shows the sound quality results and the graph in Fig. 13 shows the relation with the values emerging from the subjective polls. A close relation can be seen (Pearson coefficient $r=0.94$ ) between the quality value found in the polling and that calculated by the fuzzy inference technique. In some spaces, up to three different sound scenarios were analyzed.

The fuzzy inference methodology used also makes it possible to visualize the relationships that are established between the descriptors adopted and to interpret the degree of influence they have in the subjective definition of the soundscape. It is thus noted, for example, that high sharpness values imply high sound quality (Fig. 14) almost independently of the other variables.

High sound quality, directly related to increasing sharpness, is caused by the dominant presence of masking sounds, such as active fountains of water and voices. However, vehicle noises with high sharpness can also create higher annoyance. In this case the low sound quality is determined by the excessive low frequency content $\left(L_{\mathrm{Ceq}} L_{\mathrm{Aeq}}\right)$. As sharpness diminishes, the low frequency content represented by the $L_{\mathrm{Ceq}} L_{\mathrm{Aeq}}$ difference begins to gain importance. For low sharpness values, a relation with low content of low frequencies helps to increase the sound quality of the space. As sharpness increases, the influence of spectrum composition on quality reduces. A similar relationship is seen between sharpness and loudness. Loudness is important in the middle range of sharp ness values. Lower loudness enables an increase in the sound qual ity of a space. In this case, loudness has a greater influence in spaces where sharpness is low.

\section{Conclusions}

The analysis makes it clear that the evaluation of the sound scape of an open urban space must be tackled keeping in mind the interaction between acoustic parameters and other elements 
Table 5

Inferred sound quality and by subjective study.

\begin{tabular}{lll}
\hline & Sound quality & \\
\cline { 2 - 3 } & Calculated by fuzzy & $\begin{array}{l}\text { From subjective } \\
\text { study }\end{array}$ \\
\hline Plaza San Martin & 2.46 & 2.50 \\
Fundador & 2.90 & 3.50 \\
& 2.63 & 2.50 \\
Santa Catalina & 2.73 & 3.00 \\
& 2.55 & 3.00 \\
Compañía & 3.39 & 3.20 \\
& 2.69 & 2.50 \\
Vélez Sarsfield & 2.96 & 3.00 \\
Plaza Colón & 3.21 & 3.50 \\
Plaza Italia & 2.40 & 2.40 \\
& 2.30 & 2.40 \\
Paseo Sobremonte & 2.45 & 2.00 \\
& 2.69 & 2.50 \\
Plaza de la & 2.66 & 2.60 \\
Intendencia & 4.67 & 4.60 \\
Paseo del Buen Pastor & 2.43 & 1.20 \\
Plaza España & 2.44 & 1.60 \\
Paseo de las Artes & 2.00 & 4.20 \\
Pearson correlation coefficient $r=0.94$ & 1.80 \\
& 2.67 & 2.50 \\
& 2.89 & 2.70 \\
& 3.80 & 4.00 \\
& & \\
& &
\end{tabular}

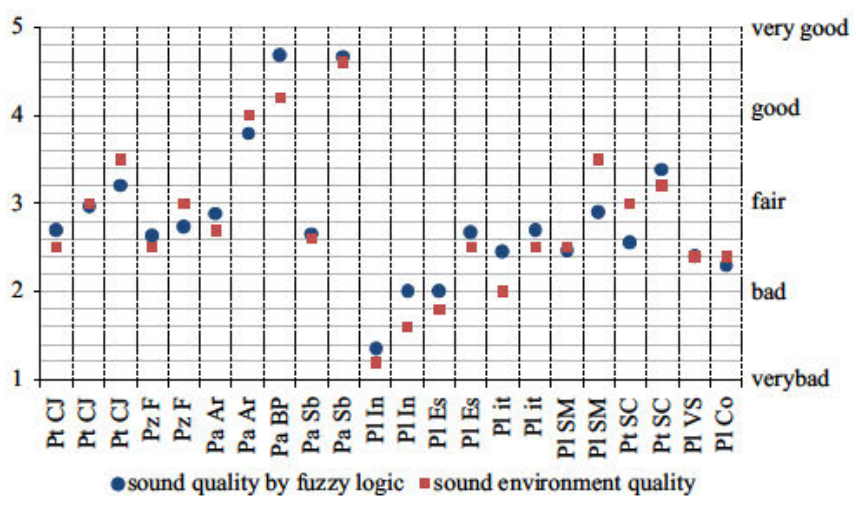

Fig. 13. Comparison of inferred and surveyed quality levels.

characteristic of the environment. The level of sound pressure is an important parameter in evaluating a sound environment, but the studies clearly show that there is no direct correlation between discomfort from noise and the physical sound parameters. The analysis confirms that the continuous equivalent sound level can not be the only objective parameter characterizing the soundscape of outdoor spaces. Noise levels below $6570 \mathrm{dBA}$ are more influ enced by the character of the sound source than by the general sound level. In soundscapes, it is proposed to use the concept of displeasure for situations in which sound levels are below this range.

The sound quality of urban spaces, within the range of accept able sound levels in which no discomfort is caused, has been shown to depend on factors related to the subjective response of users, conditioned by cultural and social patterns. Therefore, in parallel with the analysis of the levels of presence and/or discom fort of sounds of a soundscape and of the sound level of the envi ronment in general, variables related with the users' perceptions should be taken into account, for which the urban soundscape analysis is complemented with psychoacoustic indicators used in sound quality studies. The perceived sound quality of a soundscape depends, in accordance with the ISO 129131 [57], on the context, on the auditory sensations, on the expectation and even on the cul tural background.

We conclude that, when the $L_{\mathrm{Aeq}}$ sound pressure level is not above $6570 \mathrm{dBA}$, the sound quality of a soundscape can be studied based on four combined descriptors: sharpness, loudness, $L_{10} L_{90}$ and $C_{o} G$ or $L_{\text {Ceq }} L_{\text {Aeq. }}$. The sound rating for each descriptor sepa rately cannot be applied or generalized to the sound environment. The latter is the set of descriptors that interact to define the sound quality of the urban space. The influence of each indicator on qual ity depends on the interrelation with the other parameters considered.

Fuzzy logic postulates are adopted as suitable for studying soundscapes in which the limits of acceptability or quality for each of the acoustic and psychoacoustic descriptors involved in the soundscape rating are not precise. This non linear interrelation between the descriptors approximates to the postulates of fuzzy logic, which justifies adopting this methodology as a tool for the analysis of sound quality in outdoor spaces, based on the interrela tion of the acoustic descriptors with the subjective response.

The fuzzy logic model proposed aims at defining a mechanism to enable soundscape rating by analyzing the acoustic and psy choacoustic indicators and descriptors identified as characterizing the sound quality of the space. The rules for the model were defined using the conclusions of the cross analysis of physical, psy chophysical and perceptual sound quality variables resulting from the study made and are thus valid for the sociocultural situation proper to the spaces studied. A very accurate relation is achieved between the rating reached in the survey with the value calculated with the fuzzy logic technique.
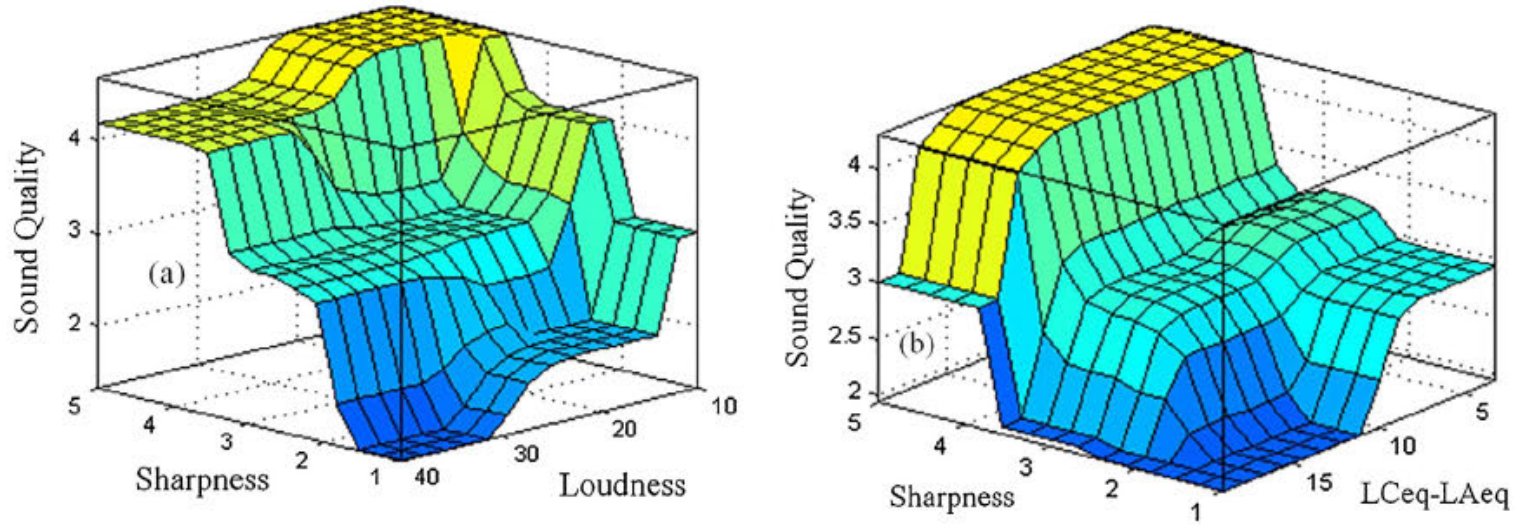

Fig. 14. Sharpness-loudness (a) and sharpness $L_{\mathrm{Ceq}}-L_{\mathrm{Aeq}}$ relationships with sound quality. 


\section{References}

[1] Yu L, Kang J. Effects of social, demographical and behavioral factors on the sound level evaluation in urban open spaces. J Acoust Soc Am 2008;123:772-83. http://dx doi org/10 1121/12821955

[2] Davies WJ, Adams MD, Bruce NS, Cain R, Carlyle A, Cusack P, et al. Perception of soundscapes: an interdisciplinary approach. Appl Acoust 2013;74:224-31. http://dx.doi.org/10.1016/j.apacoust.2012.05.010.

[3] Environmental Protection Agency (EPA). Noise effects handbook. A desk reference to health and welfare effects of noise. USA: Noise Pollution Clearinghouse; 1981.

[4] Berglund B, Lindvall T. Community noise. Arch Cent Sens Res 1995;2:1-195.

[5] Fields J et al. Standardized general-purpose noise reaction questions for community noise surveys: research and a recommendation. J Sound Vib 2001;242:641-79. http://dx doi org/10 1006/jsvi 20003384.

[6] Arana M, Martín RS, Nagore I, Pérez D. Using noise mapping to evaluate the percentage of people affected by noise. Acta Acust United Acust 2009;95:550-4. http://dx doi org/10 3813/AAA 918180.

[7] Sommerhoff J, Recuero M, Suárez E. Community noise survey of the city of Valdivia, Chile. Appl Acoust 2004;65:643-56. http://dx.doi.org/10.1016/j. apacoust.2004.01.003.

[8] Suárez E, Recuero M. Metodologías Simplificadas para Estudios en Acústica Ambiental: Aplicación en la Isla de Menorca-Tesis Doctoral (simplified methodologies for studies in environmental acoustics: application on the Island of Menorca - doctoral thesis), Programa de Doctorado en Ingeniería Acústica, Departamento de Mecánica y Fabricación, E.T.S. de Ingenieros Industriales. España: Universidad Politécnica de Madrid; 2002.

[9] Recuero M. Estudio Subjetivo del Ambiente Acústico en los Municipios de la Comunidad de Madrid (subjective study of acoustic environment in communes of Madrid). In: Conferencia I Congreso Iberoamericano de Acústica. Florianópolis. Brasil; 1998.

[10] Yang W, Kang J. Acoustic comfort evaluation in urban open public spaces. App Acoust 2005;66:211-29. http://dx.doi.org/10.1016/j.apacoust.2004.07.011.

[11] De Coensel B, Botteldooren D. The quiet rural soundscape and how to characterize it. Acta Acust United Acust 2006;92:887-97.

[12] Raimbault M, Lavandier C, Bérengier M. Ambient sound assessment of urban environments: field studies in two French cities. Appl Acoust 2003:64:1241-56. http://dx doi org/10 1016/S0003-682X(03)00061-6

[13] Irvine KN, Devine-Wright P, Payne SR, Fuller RA, Painter B, Gaston KJ. Green space, soundscape and urban sustainability: an interdisciplinary, empirical study. Local Environ Int J Justice Sustain 2009;14:155-72. http://dx doi org $10.1080 / 13549830802522061$.

[14] Raimbault M, Dubois D. Urban soundscapes: experiences and knowledge. Cities 2005;22:339-50. http://dx.doi.org/10.1016/i.cities.2005.05.003.

[15] Zhang M, Kang J. Towards the evaluation, description, and creation of soundscapes in urban open spaces. Environ Plan B Plan Des 2007;34:68-86. http://dx doi org/10 1068/b31162.

[16] Szeremeta B, Zannin PHT. Analysis and evaluation of soundscapes in public parks through interviews and measurement of noise. Sci Total Environ 2009;407:6143-9. http://dx doi org/10 1016/j scitotenv 200908039

[17] Gjestland T. Current research topics and problems: the role of ICBEN. J Sound Vib 2002;250:1. http://dx doi org/10 1006/isvi 20013883.

[18] Rychtarikova M, Vermeir G, Domecka M. The application of the soundscape approach in the evaluation of the urban public spaces. J Acoust Soc Am 2008;123:3810. http://dx.doi.org/10.1121/1.2935528.

[19] Kang J, Zhang M. Semantic differential analysis of the soundscape in urban open public spaces. Build Environ 2010;45:150-7. http://dx.doi.org/10.1016/i. buildenv.2009.05.014

[20] Genuit K, Fiebig A, Schulte-Fortkamp B. Relationship between environmental noise, sound quality, soundscape. J Acoust Soc Am 2012;132:1924. http://dx. doi.org/10.1121/1.4755063.

[21] Axelsson Ö, Nilsson ME, Berglund B. A principal components model of soundscape perception. J Acoust Soc Am 2010;128:2836-46. http://dx.doi. org/10.1121/1.3493436.

[22] Rychtáriková M, Vermeir G. Soundscape categorization on the basis of objective acoustical parameters. Appl Acoust 2013;74:240-7. http://dx.doi. org/10.1016/i.apacoust.2011.01.004.

[23] De Coensel B, Vanwetswinkel S, Botteldooren D. Effects of natural sounds on the perception of road traffic noise. J Acoust Soc Am 2011;129:EL148-53. http://dx doi org/10 1121/1356707

[24] Zannin PHT, Calixto A, Diniz FB, Ferreira JAC. A survey of urban noise annoyance in a large Brazilian city: the importance of a subjective analysis in conjunction with an objective analysis. Environ Impact Assess Rev 2003;23:245-55. http://dx doi org/10 1016/S0195-9255(02)00092-6

[25] Llimpe CE, Recuero M, Moreno JN. Encuestas sobre molestias causadas por ruido en el Centro Histórico de Lima, Perú: Análisis Subjetivo relacionado al estudio objetivo (surveys on noise annoyance in the historical center of Lima, Peru: subjective analysis related to the objective study). In: V Congreso Iberoamericano de Acústica, Santiago (Chile); 2006.

[26] Tse MS, Chau CK, Choy YS, Tsui WK, Chan CN, Tang SK. Perception of urban park soundscape. J Acoust Soc Am 2012;131:2762. http://dx doi org/10 1121/ 13693644

[27] Yang W, Kang J. Soundscape and sound preferences in urban squares: a case study in Sheffield. J Urban Des 2005;10:61-80. http://dx doi org/101080/ $\underline{13574800500062395}$
[28] Guastavino C. The ideal urban soundscape: investigating the sound quality of French cities. Acta Acust United Acust 2006:92:945-51.

[29] Jambrošić K, Horvat M, Domitrović H. Assessment of urban soundscapes with the focus on an architectural installation with musical features. J Acoust Soc Am 2013;134:869-79. http://dx.doi.org/10.1121/1.4807805.

[30] Schulte-Fortkamp B. Soundscape as a resource to balance the quality of an acoustic environment. J Acoust Soc Am 2015;137:2255. http://dx.doi.org/ $10.1121 / 1.4920225$.

[31] Cain R, Jennings P, Poxon J. The development and application of the emotional dimensions of a soundscape. Appl Acoust 2013;74:232-9. http://dx doi org/ $101016 / \mathrm{i}$ apacoust 201111006

[32] Pheasant R, Horoshenkov K, Watts G, Barrett B. The acoustic and visual factors influencing the construction of tranquil space in urban and rural environments tranquil spaces-quiet places? J Acoust Soc Am 2008;123:1446-57. http://dx doi org/10 1121/12831735

[33] Viollon S, Lavandier C, Drake C. Influence of visual setting on sound ratings in an urban environment. Appl Acoust 2002;63:493-511. http://dx.doi.org/ 10.1016/S0003-682X(01)00053-6.

[34] Carles JL, Barrio IL, De Lucio JV. Sound influence on landscape values. Landsc Urban Plan 1999;43:191-200. http://dx.doi.org/10.1016/S0169-2046(98)00112-1.

[35] Carles J, López Barrio I. Importance of personal, attitudinal and contextual variables in the assessment of pleasantness of the urban sound environment. In: 19th International congress on acoustics (ICA). Madrid (Spain); 2007.

[36] Pheasant RJ, Fisher MN, Watts GR, Whitaker DJ, Horoshenkov KV. The importance of auditory-visual interaction in the construction of "tranquil space". J Environ Psychol 2010;30:501-9. http://dx.doi.org/10.1016/ i.jenvp.2010.03.006.

[37] Hong JY, Jeon JY. Designing sound and visual components for enhancement of urban soundscapes. J Acoust Soc Am 2013;134:2026-36. http://dx.doi.org/ $10.1121 / 1.4817924$.

[38] Nilsson ME, Jeon J.Y., Rådsten-Ekman M, Axelsson Ö, Hong JY, Jang HS. A soundwalk study on the relationship between soundscape and overall quality of urban outdoor places. In: Acoustics 2012. Hong Kong; 2012.

[39] Hume K, Ahtamad M. Physiological responses to and subjective estimates of soundscape elements. Appl Acoust 2013;74:275-81. http://dx doi org/ $101016 /$ i apacoust 201110009.

[40] Hall DA, Irwin A, Edmondson-Jones M, Phillips S, Poxon JEW. An exploratory evaluation of perceptual, psychoacoustic and acoustical properties of urban soundscapes. Appl Acoust 2013;74:248-54. http://dx.doi.org/10.1016/i. apacoust.2011.03.006.

[41] Özcan E, van Egmond R. Basic semantics of product sounds. Int J Des $2012 ; 6: 41-54$

[42] Jurc R, Jiříček O, Brothánek M. Methods for the assessment of pleasantness in sound quality. Noise Contr Eng J 2010;58(1):62-6. http://dx doi org/10 3397/ 1327010

[43] Genuit K. Status of psychoacoustics in noise analysis. J Acoust Soc Am 2015;137(4):2291. http://dx doi org/10 1121/1 4920362.

[44] Genuit K, Schulte-Fortkamp B, Fiebig A. Psychoacoustics triggering the soundscape standardization. J Acoust Soc Am 2013;134(5):4021. http://dx. doi.org/10.1121/1.4830681.

[45] Semidor C. Characterization of urban soundscape using psychoacoustic criteria. In: Internoise 2005. Rio de Janeiro; 2005.

[46] Chartier F, Semidor C. Evaluation of Sound environment characteristics: comparative study between objective and subjective criteria. In: Proc ASA/ CAA, Vancouver (Canada); 2005.

[47] Genuit K, Fiebig A. Psychoacoustics and its benefit for the soundscape approach. Acta Acust United Acust 2006;92:952-8.

[48] Zadeh L. Fuzzy sets. Inform Contr 1965;8:338-53. http://dx.doi.org/10.1016/ S0019-9958(65)90241-X.

[49] Zaheeruddin, Garima. A neuro-fuzzy approach for prediction of human work efficiency in noisy environment. Appl Soft Comput 2006;6:283-94. http://dx. doi.org/10.1016/i.asoc.2005.02.001.

[50] Verkeyn A. Fuzzy modeling of noise annoyance. Doctoral thesis. Belgium: Universidad de Gent; 2004

[51] Zaheeruddin, Jain VK, Singh GV. A fuzzy model for noise-induced annoyance. IEEE Trans Syst Man Cybern Part A Syst Hum 2006;36:697-704. http://dx doi org/10 1109/TSMCA 200585134.

[52] Givargis S. A fuzzy expert system capable of computing LA, max for the Tehran-Karaj commuter train. Appl Acoust 2009;70:200-7. http://dx doi org/ $101016 /$ j apacoust 200712010.

[53] Zaheeruddin, Jain VK. An expert system for predicting the effects of speech interference due to noise pollution on humans using fuzzy approach. Expert Syst Appl 2008;35:1978-88. http://dx.doi.org/10.1016/j.eswa.2007.08.10.

[54] Recuero M. Mapas de ruido. Determinación del error cometido en medidas de campo, para diferentes duraciones de las Muestras (noise maps. Determination of the error in field measurements for different durations of samples), Revista de Acústica SEA, vol. 18(3-4); 1997. p. 89-93.

[55] Cabrera D, Ferguson S, Schubert E. PsySound3: software for acoustical and psychoacoustical analysis of sound recordings. In: Proc int conf audit disp; 2007. p. 356-63.

[56] Semidor C, Barlet A, Chartier F. Soundscape approach as a tool for urban design. Second part: frequentation, use and sound environment perception in four cities in Europe: Barcelona, Bristol, Brussels and Genoa. European Commission DG Research; 2007.

[57] International Organization for Standardization (ISO). Acoustics - Soundscape Part 1: Definition and conceptual framework. ISO 12913-1; 2014. 